\title{
Review of Keloid Patients with Clinical Experience
}

\section{Young Hoo Joh, Seung Jun Shin, Myong Chul Park, Dong Ha Park}

Department of Plastic and Reconstructive Surgery, Ajou University Hospital, Suwon, Korea

No potential conflict of interest relevant to this article was reported.
Background Keloid management can be difficult and frustrating, and the mechanisms underlying keloid formation are only partially understood. Despite many studies of the pathogenesis and cause, little is known of the predisposing factors or the diathesis. Therefore, we evaluated patients with keloid for 13 years clinical experience, with the goal of considering the causative factors and physical disposition of keloid.

Methods We evaluated 107 patients ( 38 males, 69 females; median age 22.31 years, range 7-58 years) who visited the department of plastic and reconstructive surgery from March 1998 to December 2010. The patients' chart and clinical photo were reviewed for the study.

Results Etiologies were an intended wound like piercing or surgical wound $(n=39)$, avulsion flap injury $(n=30)$, laceration $(n=29)$ and burn $(n=9)$. The location were the head and neck $(n=38)$, trunk $(n=23)$, upper extremity $(n=21)$, lower extremity $(n=16)$ and face $(n=9)$. Patients with more than overweight ( $>23 \mathrm{~kg} / \mathrm{m}^{2}$, Body mass index) were 84 in 107 patients (78.5\%) with keloids.

Conclusions In the care of the keloids, patient information, particularly sex, age and body mass index, it may be useful indicators for expecting prognosis of the patients and treating with proper management. Particularly, large-scale accurate follow-up observations on obese patients will be critical.

Keywords Age, Body mass index, Epidemiology, Etiology, Keloid

\section{INTRODUCTION}

Despite numerous basic studies on wound healing, keloids remain difficult to treat because of a lack of effective preventive or treatment methods. They have ugly external appearances and hinder daily life activities, as they are occasionally accompanied by unbearable itchiness or pain. In particular, if they occur in exposed areas of the face or upper and lower limbs, they will induce cosmetic issues that can impart physical and mental anguish to patients, hindering social activities [1].

While hypertrophic scars tend to be limited to damaged areas and gradually disappear after 1-2 years, keloids differ, as they con-

Received: Aug 4, 2014 Revised: Oct 1, 2014 Accepted: Oct 6, 2014 Correspondence: Dong Ha Park Department of Plastic and Reconstructive Surgery, Ajou University Hospital, 164 Worldcup-ro, Yeongtong-gu, Suwon 443-721, Korea. E-mail: growhand@hanmail.net

Copyright (@ 2014 The Korean Society for Aesthetic Plastic Surgery.

This is an Open Access article distributed under the terms of the Creative Commons Attribution Non-Commercial License (http://creativecommons.org/licenses/by-nc/3.0/) which permits unrestricted non-commercial use, distribution, and reproduction in any medium, provided the original work is properly cited. www.e-aaps.org tinue to spread and cause damage [2]. Since it is not easy to distinguish these two diseases, as they only display differences in biochemical and pathological characteristics, hypertrophic scars and keloids are regarded as the same disease process with differences only in the extent of damage $[2,3]$.

Current treatment methods include chemical treatments, such as local injections of adrenocorticotrophic hormone and the use of silicone gel, physical methods including compression therapy and radiation therapy, and surgical procedures. These treatment methods are used alone or in combination [4-6], and are limited in their application if the keloid-affected area is broad. In particular, injections of adrenocorticotrophic hormone for the treatment of broad areas cause severe pain at the time of injection and cannot be used for prolonged periods of time, as several injections in a short period of time can cause side effects [1]. These methods are limited in the treatment of disease due to the high rate of recurrence observed under long-term follow up [4].

Currently, as people emphasize their quality of life, keloids have become the subject of assertive treatments. We gathered data from 13 years of clinical analysis of keloids. This study analyzed various indices of patients with keloids, with the aim to compare the caus- 
ative factors and physical dispositions of keloids.

\section{METHODS}

Retrospective analysis was carried out for 165 patients who underwent consultation, treatment, and surgery for keloids at the plastic surgery department from March 1998 to December 2010. Among the patients who visited the hospital, 58 patients were excluded, leaving 107 patients as the final subjects of this study. Excluded patients included those who did not display symptoms of keloids and those for whom a retrospective analysis was not possible due to insufficient medical records and/or inaccessibility for an interview. Data on age, gender, height, and weight, as well as past history of the patient and family were confirmed through a review of medical care records, questionnaires on medical conditions, and scientific tests; correlations between each of the indices were analyzed. Based on scientific tests and systematic questionnaires on medical conditions, the patients were included in the study if the keloids exhibited one or more of the following symptoms: protruding lesion that induced itchiness, pain, change in the color of the scar, and/or cosmetic or functional problems following skin damage (Table 1). Weight and height were obtained for the calculation of body mass index (BMI). In addition, lesions were categorized in terms of the type and areas of external wounds to analyze where the keloids occurred.

Age was determined as age at the time of manifestation and categorized into age brackets of less than 10 years old, teens, 20s, 30s, and 40s. Height and weight were determined at the time of the patient's visit to the hospital. The BMI (Kaup index, $\mathrm{kg} / \mathrm{m}^{2}$ ) of each patient was computed on the basis of these data and used as the criterion of the level of obesity. BMI was categorized into less than $18.5 \mathrm{~kg} / \mathrm{m}^{2}$ (underweight), less than $23 \mathrm{~kg} / \mathrm{m}^{2}$ (normal weight), less than $25 \mathrm{~kg} / \mathrm{m}^{2}$ (overweight), and greater than $25 \mathrm{~kg} / \mathrm{m}^{2}$ (obese). These values differed from the standards used in Western countries, as they were in accordance with the Asian standard published by the World Health Organization in 2004 [7]. Type of external wounds comprised four categories in our study: simple laceration, avulsion, burn, and intended wound. Piercings for earrings and surgical wounds were included in the category of intended external wound. Areas of lesions were determined to be the head and neck, with the exception of the face, anterior thorax, and body trunk including the abdomen and back, upper limbs including the shoul-

Table 1. Inclusion criteria

\begin{tabular}{l} 
Keloid symptoms \\
\hline Protruding from the original wound \\
Itching \\
Pain \\
Color change (red, purple, dark brown) \\
Severe aesthetic problems or dysfunction
\end{tabular}

der, and lower limbs. Correlations between each of these values and keloids were analyzed. Statistical analysis was performed using SPSS version 12.0 for Windows (SPSS, Chicago, IL, USA). We used the Student's t-test and rank sum test for evaluations of statistical relationship.

\section{RESULTS}

Of the 165 initially chosen patients, 58 were excluded, leaving 107 patients as final subjects. Subjects were composed of 38 males (35.5\%) and 69 females (64.5\%). The average age of the patients was 22.31 years (male, 25.3 years; female, 20.1 years). The age distribution included 22 patients under 10 years of age (20.6\%), 38 in their teens (35.5\%), 26 in their 20s (24.3\%), 11 in their 30s (10.3\%), and 10 older than 40 years of age (9.3\%). Accordingly, most subjects were in their teens followed by those in their 20 s and under the age of 10 years. Nineteen subjects had a past personal history of keloids, and seven had a past family history.

With regard to the causes of these lesions, intentional external wounds, such as surgical wounds or piercings accounted for the largest proportion with 39 cases (36.4\%), followed by avulsion (30 cases, $28.0 \%$ ), simple laceration ( 29 cases, $27.1 \%$ ), and burns ( 9 cases, $8.4 \%$ ). The head and neck, with the exception of the face, accounted for the largest area of manifestation with 38 cases (35.5\%), followed by the body trunk (23 cases, $21.5 \%$ ), upper limbs (21 cas-

Table 2. Patient data

\begin{tabular}{|c|c|c|c|}
\hline & Male ( $\mathrm{n}=38$ ) & Female ( $\mathrm{n}=69)$ & P-value \\
\hline Age in years, mean (SD) & $25.3(3.11)$ & $20.1(2.95)$ & 0.81 \\
\hline$<10$ & $6[15.4]$ & $16(18.7)$ & $0.012^{\mathrm{al}}$ \\
\hline $10-19$ & $6(19.8)$ & 32 (43.5) & \\
\hline $20-29$ & 13 (31.9) & 13 (23.5) & \\
\hline $30-39$ & $6(11.5)$ & $5(11.1)$ & \\
\hline$>40$ & $7(20.6)$ & 3 (15.2) & \\
\hline BMI, n (\%) & & & 0.075 \\
\hline Normal & 13 (34.2) & 10 (14.5) & \\
\hline Overweight & 19 (50.0) & 42 (60.9) & $0.020^{\mathrm{bl}}$ \\
\hline Obese & $6(15.8)$ & $17(24.6)$ & \\
\hline Location, n (\%) & & & 0.311 \\
\hline Face & $6(15.8)$ & $3(4.3)$ & \\
\hline Head and neck & 9 (23.7) & $29(42.2)$ & \\
\hline Trunk & 10 (26.3) & 13 (18.8) & \\
\hline Upper limb & $8(21.1)$ & 13 (18.8) & \\
\hline Lower limb & 5 (13.2) & $11(15.9)$ & \\
\hline Cause, n (\%) & & & 0.165 \\
\hline Laceration & 15 (39.5) & 14 (20.3) & \\
\hline Avulsion & $11(28.9)$ & 19 (27.5) & \\
\hline Burn & $5(13.2)$ & $4(5.8)$ & \\
\hline Intended & $7(18.4)$ & $32(46.4)$ & \\
\hline
\end{tabular}

BMI, body mass index.

alThis value resulted from an analysis of the age-linked distribution between males and females; ${ }^{b}$ This value resulted from the analysis comparing the normal group with the overweight/obese groups. 
es, 19.6\%), lower limbs (16 cases, $15.0 \%$ ), and face (9 cases, $8.4 \%$ ). No patient had a BMI less than $18.5 \mathrm{~kg} / \mathrm{m}^{2}$, whereas there were 23 normal-weight patients (21.5\%) with a BMI from $18.5 \mathrm{~kg} / \mathrm{m}^{2}$ to 23 $\mathrm{kg} / \mathrm{m}^{2}, 61$ overweight patients (57.0\%) with a BMI between $23 \mathrm{~kg} /$ $\mathrm{m}^{2}$ and $25 \mathrm{~kg} / \mathrm{m}^{2}$, and 23 obese patients (21.5\%) with a BMI exceeding $25 \mathrm{~kg} / \mathrm{m}^{2}$. Therefore, 84 patients were overweight or obese, accounting for $78.5 \%$ of all subjects (Table 2).

Analysis was carried out to determine whether there were differences in the characteristics of keloid patients by gender. Differences in the age-linked distribution were apparent between males and females $(\mathrm{P}=0.012)$, whereas more males were older than 20 years of age, and females were most numerous in those younger than 20 years of age.

The average BMI was $24.24 \mathrm{~kg} / \mathrm{m}^{2}$ for males and $25.41 \mathrm{~kg} / \mathrm{m}^{2}$ for females, which were not significantly different. Although there were no differences between groups when the BMI distribution between males and females was divided into normal weight, overweight, and obese patients $(\mathrm{P}=0.075)$, there were statistically more females than males in the overweight/obese group compared to the normal weight group $(\mathrm{P}=0.020)$. This result indicated that there were more females in the group who were overweight compared to the normal weight group (Table 2). There were no statistical relationships in the BMI distribution by age $(\mathrm{P}=0.124)$.

\section{DISCUSSION}

Keloids are defined as thick scar tissues that invade normal tissues and the cornea at the boundaries of the original injury, and appear on the skin and cornea due to deposition of excessive collagen over a prolonged period of time [8]. There are differences in the frequency and ease of manifestation, depending on the areas affected. The area with the most frequent manifestations of keloids is the anterior thorax, back, and neck, followed by the ear, shoulder, above the upper lip, the upper arm, abdomen, and the remaining areas of face [9].

Among the studies of causative factors of keloids, age has been the most studied factor. Presently, there is a trend of gender differences by age. In males, there is tends to be a much higher frequency of keloids in those over 20 years of age, whereas there tends to be a higher frequency of keloids in those under 20 years in females.

Although keloids occur frequently on the upper parts of the body, including the chest, shoulder, chin, and ears, they are not frequently found in the genital area, palm of the hand, sole of the foot, or abdomen. If keloids are found in these areas, they tend not to be severe [4]. The tensile strength of the skin has been suggested as the reason for differences in the manifestation of hypertrophic scars and keloids. As evidence to support this presumption, a report described the shrinkage of a lesion when the keloid was transplanted to the femoral region with low tensile strength; additionally, changes in tensile strength caused by induction of a wound on a collagen lattice at the time of three-dimensional culturing of fibroblasts was found to drive a change in and proliferation of the fibroblasts [10]. Presently, the head and neck areas display the highest rate followed by the body trunk, upper limbs, lower limbs, and face. The rate of occurrence was high on the head and neck, with the exception of the face, because of the large number of subjects who pierced their ears.

This study aimed to examine the relationship between obesity and the manifestation of keloids. There was no particular difficulty in computing the BMIs of the subjects, as weights and height data were available in the medical records. In Asians, including Koreans, standards used for distinctions of obesity using BMI differ from those of Western countries [7]. For Koreans, while the occurrence of keloids was substantially low at $19.5 \%$ for underweight people with a BMI less than $18.5 \mathrm{~kg} / \mathrm{m}^{2}$ and those with normal weight (a BMI ranging from 18.5 to $23 \mathrm{~kg} / \mathrm{m}^{2}$ ), the rate was higher for overweight people with a BMI between $23 \mathrm{~kg} / \mathrm{m}^{2}$ and $25 \mathrm{~kg} / \mathrm{m}^{2}$, as well as in obese people with a BMI greater than $25 \mathrm{~kg} / \mathrm{m}^{2}$. The difference between the two groups was statistically significant, and this statistical result is noted in our study.

The fact that obesity affects changes in the structure and function of collagen, which in turn aggravates wound healing, has been demonstrated through animal studies. Enser and Avery [11] asserted that obese rats have skin that is dynamically weaker and generates lower hydrothermal isometric force compared to slim rats. It is thought that the dynamic tensile force of the skin is reduced, because it fails to accumulate collagen on the surface in obese rats, which also display slow healing of the wound and reduced accumulation of collagen in the wound [12]. Therefore, continuously high tensile force may be generated in various areas of the body which could possibly increase the occurrence of keloids.

Epidemiological studies on obesity and the production of sebum have not been reported. However, obesity affects the differentiation of basal keratinocytes in the pilosebaceous duct [13]. In addition, frequent elevations in the levels of androgens (hyperandrogenism is thought to be induced by obesity), insulin, and growth hormone can be observed in obese people, activating sebaceous glands [14], which increases the activity of sebum that affects the metabolic synthesis of collagen and is thought to affect the manifestation of keloids.

In addition, other studies reported that obesity is related to serious changes in the circulation of the blood in the skin. Obesity is a key cause of the failure of capillary microvessel function, which in turn is related to changes in microvessels and high blood pressure [15]. Loffler et al. [16] illustrated that the circulation in the skin was elevated in those with a high BMI, but the speed of cells within the blood vessel becomes very slow. These facts support the view that obesity negatively influences wound healing. Should the healing of the wound be delayed or if there is a problem in this process, the manifestation of keloids may increase.

An association of keloids and BMI, as an indication of the level 
of obesity, has been rarely reported until now and is limited to the particular area of the body [17], even though our study investigated all body areas. The present finding that the level of obesity as measured by BMI can be used as an index for the prevention and treatment of keloids has important implications in Korea and other countries in which obesity rates are increasing. Measuring the partial obesity ratio for the area of injury, the tensile force for each area, the metabolic rate of collagen synthesis for each area, and changes in the symptoms of keloids in accordance with changes in BMI from early childhood could compose an interesting research task. Discussions on BMI should assure statistical significance through an increased number of subjects, and evaluations should be collected through continuous observations on patient progress and treatment methods in the future.

A retrospective review of the medical treatment records of 107 patients with keloids who visited the plastic surgery department was carried out. Causative factors were identified through a comparative analysis of characteristics in accordance with clinical factors, including gender, age, types and locations of wounds, and the level of obesity. There were no differences between females and males. While there were many female patients under 20 years of age, there were a significantly larger number of male patients over 20 years of age. Although a high number of keloids tended to be located on the head and neck, including the earlobes, it was not statistically significant. Similarly, marked differences in each of the causes of intentional incision wounds were not statistically different. Among the keloid patients, there were many subjects who were overweight and obese, with a BMI of at least $23 \mathrm{~kg} / \mathrm{m}^{2}$. Large scale, follow-up observations on obese subjects will be necessary for detailed results.

\section{REFERENCES}

1. Lee WJ, Lew DH, Chung S, et al. A clinical evaluation of safety and efficacy of Tranilast for keloid and hypertrophic scars: a prospective, onegroup, open-labeled study. J Korean Soc Plast Reconstr Surg 2002;29: 162-8.

2. Burd A, Huang L. Hypertrophic response and keloid diathesis: two very different forms of scar. Plast Reconstr Surg 2005;116:150e-7e.

3. Lee SH, Lee HG, Kim JM. Clinical analysis of postburn hypertrophic scar/keloid. Korean J Dermatol 1997;35:638-44.

4. Al-Attar A, Mess S, Thomassen JM, et al. Keloid pathogenesis and treatment. Plast Reconstr Surg 2006;117:286-300.

5. Chung JH, Burm JS, Lee JW, et al. Surgical treatment of burn induced helical keloid with excision and full-thickness skin grafting. J Korean Soc Plast Reconstr Surg 2002;29:230-4.

6. Kelly AP. Medical and surgical therapies for keloids. Dermatol Ther 2004;17:212-8.

7. WHO Expert Consultation. Appropriate body-mass index for Asian populations and its implications for policy and intervention strategies. Lancet 2004;363:157-63.

8. Doornbos JF, Stoffel TJ, Hass AC, et al. The role of kilovoltage irradiation in the treatment of keloids. Int J Radiat Oncol Biol Phys 1990;18: 833-9.

9. Kang KM, Choi IB, Kim IA, et al. Effects of postoperative radiation therapy for prevention of keloids and hypertrophic scars. J Korean Soc Ther Radiol 1997;15:269-76.

10. Shaffer JJ, Taylor SC, Cook-Bolden F. Keloidal scars: A review with a critical look at therapeutic options. J Am Acad Dermatol 2002;46:S6397.

11. Enser M, Avery NC. Mechanical and chemical properties of the skin and its collagen from lean and obese-hyperglycaemic (ob/ob) mice. Diabetologia 1984;27:44-9.

12. Goodson WH 3rd, Hunt TK. Wound collagen accumulation in obese hyperglycemic mice. Diabetes 1986;35:491-5.

13. Cordain L. Implications for the role of diet in acne. Semin Cutan Med Surg 2005;24:84-91.

14. Yosipovitch G, DeVore A, Dawn A. Obesity and the skin: skin physiology and skin manifestations of obesity. J Am Acad Dermatol 2007; 56:901-16.

15. de Jongh RT, Serne EH, Ijzerman RG, et al. Impaired microvascular function in obesity: implications for obesity-associated microangiopathy, hypertension, and insulin resistance. Circulation 2004;109:252935.

16. Loffler H, Aramaki JU, Effendy I. The influence of body mass index on skin susceptibility to sodium lauryl sulphate. Skin Res Technol 2002; 8:19-22.

17. Park TH, Seo SW, Kim JK, et al. Outcomes of surgical excision with pressure therapy using magnets and identification of risk factors for recurrent keloids. Plast Reconstr Surg 2011;128:431-9. 